International Journal of Advanced Biological and Biomedical Research Available online at http:www.ijabbr.com

Volume 8, Issue 1 (2020) pp. 40-57

DOI: 10.33945/SAMI/IJABBR.2020.1.5

Original Article

\title{
Studies on the Effect of Herbicide, Imazethapyr on Population Loss Percentage of Natural Enemies in Established Alfalfa Farms in Iran
}

\section{Mohammad Raoofi1,*, Mohammad Taghi Alebrahim¹, Somayeh Giti², Mohammad Khanjani ${ }^{3}$, Mahnaz Akbari ${ }^{4}$, Mohammad Ali Baghestani ${ }^{5}$}

\author{
${ }^{1}$ Department of Agronomy and Plant Breeding, Faculty of Agriculture and Natural \\ Resources, University of Mohaghegh Ardabili; Ardabil, Iran \\ ${ }^{2}$ Weed Science Researcher. Member of Young Researchers and Elite club, Islamic Azad \\ University, Iran \\ ${ }^{3}$ Department of Plant Protection, College of Agriculture, Bu-Ali Sina University, Hamedan, \\ Iran \\ ${ }^{4}$ University College of Omran and Tosseeh, Hamedan, Iran \\ ${ }^{5}$ Professor, Department of Weed Research, Plant Pest and Disease Research Institute, \\ Tehran, Iran \\ *Corresponding Author E-mail: m.raoofy@gmail.com
}

Received: 30 May 2019, Revised: 25 August 2019, Accepted: 30 August 2019

\begin{abstract}
The current study evaluated the negative effects of different doses of Imazethapyr on the population density of some natural enemies such as ladybug, earwig and Carabid beetles. The experiment was carried out on weed-infested established alfalfa farms for two consecutive growing seasons i.e. spring and summer during 2014-2015. The experiment was laid out in a randomized complete block design (RCBD) with eight treatments and four replications. The results showed that heavy doses application of Imazethapyr has negatively affected lady beetle, earwig and carabid beetle population, until one week after spraying. Severe losses were observed as incrementally with high doses of Imazethapyr; therefore, it is important not to exceed the recommended, standard dose $(0.5 \mathrm{~L} / \mathrm{ha})$.
\end{abstract}

Key words: Imazethapyr herbicide, reduced/increased doses, alfalfa, lady beetles, earwigs, and carabid beetles.

\section{Introduction}

The Order Coleoptera, having about 400,000 described species and hence constitutes the richest order of insects. This number is equal to all presently known plant species (Gaetan du Chatenet, 1986). Coleoptera is divided into three different suborders i.e. Archostemana, Adephagan, and Polyphaga. Numerous number of new Coleoptera species have been identified until now. Though the majority of large and medium-sized species have already been identified, it is estimated that a large number of smaller species, particularly in the tropical countries, currently remains 
unidentified. Thousands species of Coleoptera display a wide variety of shapes and colors. Of the Coleoptera, possess frame-like front and hind wings covering membranous, which are active only during flight. The elytra of insects in order Coleoptera meet in a suture line without touching. Other recognizable characteristics of Coleoptera are abrasive mouthpartsand a pre-thorax that is welded to the back of the body, forming a pterothorax; and an abdomen located on the elytra. The members of family Coccinellidae are commonly known as ladybird beetles or lady beetles. Their body length varies from $0.8-10 \mathrm{~mm}$. This family includes a large number of beetle species. The mature larva of most species effectively feeds on aphids, mealybugs and other soft-bodied pest species as well. Ladybird beetles may frequently be found in abundance at the gathering place of these pests. Some species of ladybird beetles are used to control mealybug pests in fruit gardens. Adult beetles often overwinter in large numbers in certain areas. Adult two-spotted lady beetles, Adaliabi punctata (Linn), often over winter inside homes and can be seen clustered on windows in autumn and winter. Although many species of lady beetle are considered to be major pests in some areas, on the alfalfa farms discussed in this study, they are considered nearly $100 \%$ beneficial for farming, especially since these farms lack common lady beetle hosts such as melon or kitchen garden plants. This polyphagous beetle can be an important aphid predator (Fox et al., 2004; Tedders and Schaefer, 1994) or a potentially harmful agent (Koch, 2003; Koch et al., 2003). Due to high population density of lady Beetles, earwigs and Carabid Beetles, the study consequently focused on these three groups of beneficial insects.

\section{Earwigs (Order Dermaptera)}

Earwigs are beneficial insects with a long, narrow body that is somewhat flattened, with clamplike Cerciat the end of abdomen. Adults may be winged or wingless; the winged types have one or two pairs of wings. Dermaptera is a polyneopteran insect order (Grimaldi \& Engel, 2005) with approximately 2,200 described species, mainly from tropical and warm temperate regions (Sakai, 1982, 1985, 1987a, 1990, 1991, 1992, 1993, 1994, 1995a, b, c, d; Steinmann, 1986, 1989a, b, 1990, 1993; Popham, 2000; Haas et al., 2012). Most earwig species are omnivorous or carnivorous insects that live in various types of naturalor semi-natural environments (Günther and Herter 1974; Renz and Kevan, 1991). Although several species are considered to be pests in gardens and agriculture (e.g. Nala lividipes (Dufour) and Labiduridae etc., (Cooper, 1992) or pest control agents (e.g. Labidura riparia (Pallas) of family Labiduridae) (Kharboutli and Mack, 1993), most of the earwig species have no direct relationship with human activities (Günther and Herter, 1974; Renz and Kevan, 1991; Costa, 2006). The difference between adult and immature earwigs is that the larval body has 10 abdominal rings, while the adult abdomen has just eight rings. Males have two ultimate pins with curved internal margins, whereas females have straight internal margins. Earwigs are active mainly at night; during the day they hide in cracks and fissures in the ground. Earwigs are such organisms that do not harm the environment; rather, they offer significant benefits to the environment, such as feeding on dead and decaying plant material in the field. It has even been reported that earwigs cause the destruction of larvae and pupae biologically (Rajabi, 1991). Earwigs dig holes in the ground, and pan traps were placed in these holes for the sampling and collecting required for this experiment.

\section{Carabid beetles}

Carabid or ground beetles belong to the order Coleoptera, suborder Adephaga, superfamily Caribidodea, and family Carabidae (Triplehornand Johnson, 2005). So far, nearly 40,000 thousand species of these beetles have been identified (Lobel and Semtana, 2003). Carabidae is 
one of the largest family of beetles. These beetles have a wide variety of body shapes, sizes, and coloring, but are mostly $4-40 \mathrm{~mm}$ in size, have a shiny black color, with a broad abdomen and ridged wing covers. Among the beetles of family Carabidae, the head width along the eyes is smaller than the pronotum width; the antennas are placed between the eyes, and the mandibles are based on the head and the legs are usually long and slim. Members of this family usually live on the ground and among green grass, and many Carabidae species are considered to be useful insects. Most of the ground beetles are phyllophagous and carnivorous hunters as well that contribute significantly to the natural control of weed species and many insect pest families, such as aphids, cicadas, Lepidoptera, Hemiptera, Diptera, scale insects, and other beetles (Kromp, 1999; Lovei and Sunderland, 1996). The taxonomy of ground beetles has been studied by many previous researchers/taxonomists. In addition to the comprehensive studies carried out by researchers such as (Arendt, 1973; Lindroth, 1974; Trautner, 1988) on the beetles of America, the UK, and Europe. (Morvan, 1974a, 1974b, 1974c, 1976, 1977, 1981) have performed extensive studies on the carabid beetles of Iran. Considering the central role of ground beetles in natural pest control and their notable role in the biodiversity of agricultural ecosystems, protection of their populations seems imperative. Unfortunately, these beetles are often exposed to many herbicides and pesticides which ultimately put their populations at a great risk. This study therefore, focused on beetle soil fauna and investigated the effects of different doses of a conventional hay herbicide, Imazethapyr, on their populations. The literature on the effects of herbicides on soil fauna is scarce, and this work can provide new insight into the dangers of herbicides.

Despite the known environmental hazards of herbicides, these compounds are still used in the world a sa key component of integrated weed management. In recent years, the herbicide share of total pesticide sales worldwide has increased (Zand et al., 2007). This increase is mainly due to greater attention being paid to weed management, the development of herbicide resistant plants, and the reduction of insecticide sales. In some countries, such as America, the share of herbicides in total pesticide sales has increased even more; based on information available in 1993, about $68 \%$ of the pesticides sold in the agricultural sector of America were herbicides (Prado et al., 1997). Today, herbicides are essential entities in the culture system of developed countries and the success of a significant portion of the crops in these countries is due to the use of herbicides. By 2006, about 52\% of all herbicides sales in the global market occurred in North America and Europe, while the share of Asian countries was $24.3 \%$ in the same year (Zand et al., 2010). Herbicides impact the environment in various ways. One of the most significant effects of herbicides on the environment is the development of herbicide resistant weeds and damage caused by remaining in subsequent alternations. In recent decades, the use of herbicides without management has made the herbicide resistance of weeds a global problem. By the middle of 2012, 387 weed biotypes of 208 plant species (122 species of monocotyledons and 86 species of dicotyledons) had shown resistance to herbicides (Heap, 2012).

In addition to the resistance risk, the environmental hazards of herbicides on non-target organisms should be placed on the agenda of environmentalists and weed experts. Initially, this was addressed in the discussion of the dangers of pesticides, and the quantity of pesticides (consumption dose or tons of effective used substances) was used as an indicator of environmental risk. Since the discovery of herbicides with low application dose, this indicator was questioned. The researchers decided to continue the program to reduce the use of pesticides; they also proposed a risk reduction program. 
One of the challenges of alfalfa production is the presence of weeds (Mighani et al., 2011; Raoofi et al., 2013). Generally, weeds will cause severe competition with the crop. In addition, weeds cause a reduction in the quality and quantity of the alfalfa crop, driving its sale price down 3360\% (Khanjani and Soleimani Pari, 2005; Khanjani, 2000). Weeds are most damaging to alfalfa fields in the first harvest (Zand et al., 2010); however, the weeds in many areas, such as Hamadan, damage all harvests (Raoofi et al., 2014). Weed control is often accomplished by the use of herbicides in the alfalfa field (Myhre et al., 1991). Six herbicides are recommended for use on alfalfa (Zand et al., 2010). (Raoofi et al., 2014) highlighted useful conclusions about the dangers of using herbicides on soil mites. Unfortunately, the effect of herbicides on non-target organisms has not been a high priority for researchers. Based on the excessive use of herbicides and the associated health risks on humans and the environment, findings of negative side effects of pesticide are reasonable and these issues have therefore been the subject of recent research. One of the most widely used herbicides for weed management in alfalfa farms is Imazethapyr (pursuit). This herbicide has a formulation of $10 \%$ solution liquid. The mode of action of this herbicide is the inhibition of acetolactate synthase (ALS) or acetohydroxy acid synthase (AHAS). This herbicide is used in the early growth of weeds in most alfalfa farms in Iran, at the rates of 0.4-1 liter per hectare. Imazethapyr was recorded in Iran in 2002 and is still the most widely used herbicide in alfalfa farms in this country

\section{Materials and methods}

To study the effect of different doses of Imazethapyr on the population of lady beetles, earwig and carabid beetles (the current experiment was carried out on Imazethapyr-treated established alfalfa farms infested with weeds. The experiment was carried out on weed-infested established alfalfa farms for the two consecutive growing seasons i.e. spring and summer during 2014-2015 in a randomized complete block design (RCBD) with eight treatments and four replications in plots with dimensions of $4 \times 6 \mathrm{~m}$ and distance plots of $1.5 \mathrm{~m}$ and distance blocks of $2 \mathrm{~m}$ from each other. The treatments of design were different doses of Imazethapyr including a standard dose, three decreased doses, and three increased doses which were applied by backpack hand sprayers. The doses were 1.2, 0.9, 0.7, 0.5, 0.4, 0.3 and 0.2 liters per hectare. Five pan traps containing $4 \%$ formalin were randomly installed in each plot to trap soil organisms with regard to margin of plots on the farm. It should be noted that, because of the mobility factors of soil fauna, samples were obtained from soil fauna before any treatments; after the lack of significant in plots and blocks, treatments were performed in terms of the lady beetle populations. Sampling was carried out 48 hours, one week, and three weeks after herbicides spraying. The collected samples targeted of natural enemies were transferred to special glass containers and with $70 \%$ alcohol solution before they were shifted to the laboratory of Entomology at Bu-Ali Sina University in Hamedan, Iran, for accurate identification. Considering that no herbicide was used in two weeding and non-weeding treatments (intervention and non-intervention); and given that, there was no intervention in experimental plots in the non-weeding treatment, hence this treatment (non-weeding) was appropriate criteria for evaluating experimental treatments. Given that, insect population damaged in non-weeding treatment was almost zero, so this treatment was considered as $100 \%$ without damage to insects and the rest of the treatments were assessed by calculating the percentage relative to these treatments. All insects that are counted in the plot's traps were calculated for each treatment. Due to the Henderson-Tilton formula (below formula), the percent mortality for the herbicide Imazethapyr doses was determined for each insect.

$$
\% \text { Efficiency }=(1-\mathrm{Ta} / \mathrm{Ca} \times \mathrm{Cb} / \mathrm{Tb}) 100
$$


$\mathrm{Ta}, \mathrm{Tb}=$ Number of insects per plot

$\mathrm{Ca}, \mathrm{Cb}=$ Number of insects in the control and after treatment

Table 1. Dose treatments

\begin{tabular}{cc}
\hline Herbicides & Dose (L/ ha) \\
\hline & 0.2 \\
& 0.3 \\
& 0.4 \\
Imazethapyr & 0.5 \\
& 0.7 \\
0.9 \\
1.2 \\
\hline
\end{tabular}

\section{Results}

The effect of the herbicide i.e. Imazethapyr on the population density ladybug (\& Larvae), earwig (\& Larvae) and Carabid beetles (\& Larvae) was significant at level of $1 \%$ (Table 2).

Table 2. Analysis variance of the population density for ladybug (\& Larvae), earwig (\& Larvae) and Carabid beetles ( $\&$ Larvae)

\begin{tabular}{cccccccc}
\hline $\begin{array}{l}\text { The source } \\
\text { of changes }\end{array}$ & $\begin{array}{c}\text { Degrees of } \\
\text { freedom }\end{array}$ & ladybug & $\begin{array}{c}\text { Ladybug } \\
\text { Larva }\end{array}$ & earwig & $\begin{array}{c}\text { Earwig } \\
\text { Larva }\end{array}$ & $\begin{array}{c}\text { Carabid } \\
\text { beetles }\end{array}$ & $\begin{array}{c}\text { Carabid } \\
\text { beetles } \\
\text { Larva }\end{array}$ \\
\hline Block & 3 & $2.08 \mathrm{~ns}$ & $2.44 \mathrm{~ns}$ & $2.57 \mathrm{~ns}$ & $2.88 \mathrm{~ns}$ & $2.11 \mathrm{~ns}$ & $2.68 \mathrm{~ns}$ \\
Treatment & 29 & $1332.05^{*}$ & $1366.04^{*}$ & 1402.05 & 1488.3 & $1298.49^{*}$ & $1287.55^{*}$ \\
Errors & 87 & 4 & 4.6 & 3.4 & 4.4 & 3.7 & 3.9 \\
CV & & 2.12 & 3.16 & 2.88 & 3.3 & 2.15 & 3.1 \\
\hline $\mathrm{ns}^{*}$ and ${ }^{* *}$ are insignificant and significant at confidence level of 1\% and 5\%, respectively
\end{tabular}

\section{Lady beetles}

The effects of herbicide were assessed according to the lady beetle populations as a proportion of the non-target organisms found in soil fauna during two-year study of alfalfa cultivation. In the first sampling in 2014, the results showed that, 48 hours after treatment, neither hand weeding nor lack of hand weeding had any devastating impact on lady beetle populations. This data was similar for both years of the study, and is completely obvious. In reviewing the effect of various doses of Imazethapyr, it was found that doses of $0.2-0.7$ (L/ha) in total, reduced lady beetle population by 5\%; at doses of 0.9-2.1 (L/ha) lady beetle losses were $17 \%$ (Figure 1). One week after spraying, the results showed a population loss of $3 \%$ when Imazethapyr was sprayed in doses of $0.2-0.7(\mathrm{~L} / \mathrm{ha}$ ) and as high as $10 \%$ when Imazethapyr was sprayed in doses of $0.9-1.2$ (L/ha). Although the loss rates were decreased when compared to the results of the first 48 hours after spraying, the destructive effect on lady beetle populations is still apparent (Figure 1). Three weeks after spraying, the effect of Imazethapyr on lady beetle losses showed a significant decline. In reviewing various doses of Imazethapyr, it was found that lady beetle populations decreased an average of $2 \%$ at dose of 
0.2-0.9 (L/ha) of Imazethapyr; three weeks after a dose of $1.2(\mathrm{~L} / \mathrm{ha})$, however, losses were just $0.4 \%$ (Figure 1 ).

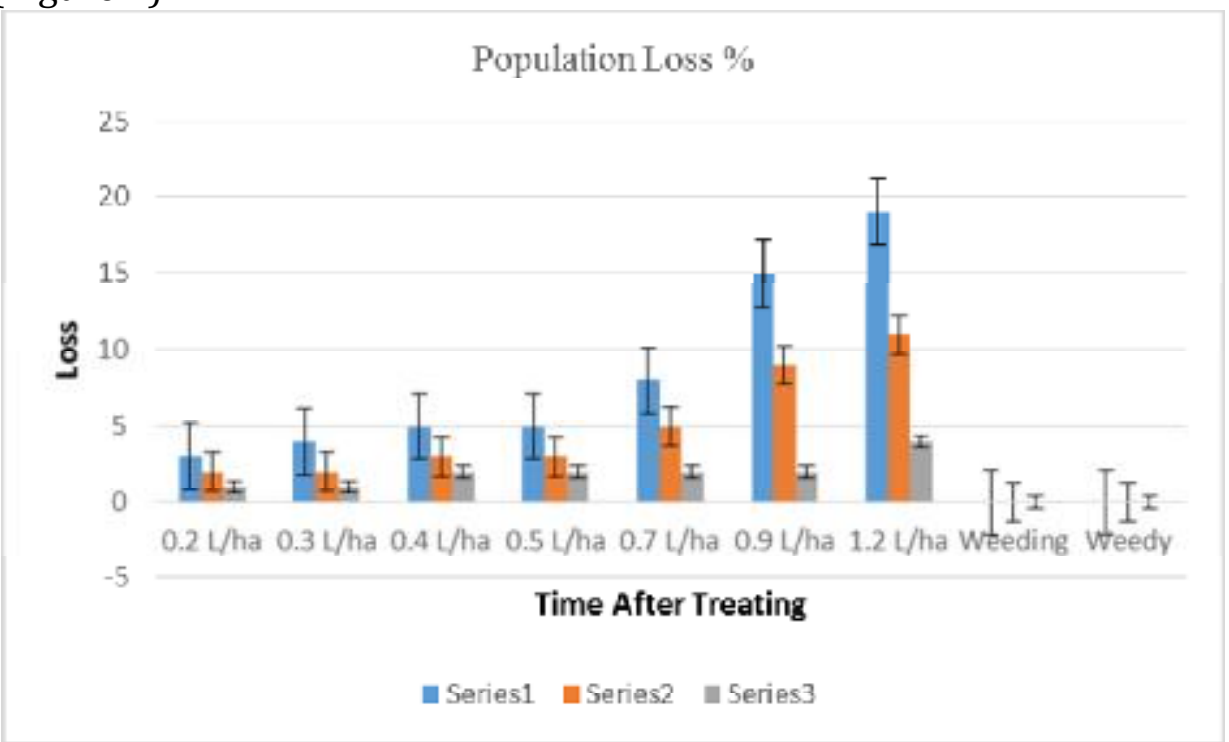

Figure1. Lady Beetle Population Loss Percentage (48 Hours-series 1, One Week-series 2 and Three Week-series 3 after Treating Herbicide Imazethapyr) -2014

The results of the second year confirmed the results of previous year. Sampling conducted in 2015 exactly matched data from the previous year: the results showed that 48 hours after spraying, the average loss with doses of $0.2-0.7$ (L/ha) was $6 \%$, while the amount of damages in final doses was calculated of 19\% (Figure 2). A week after spraying, the results were similar to those of the previous year; Imazethapyr doses from $0.2-0.7$ (L/ha) showed losses of $4 \%$, while doses of 0.9-1.2 (L/ha) showed losses of 14\% (figure 2). Finally, after three weeks of spraying, it was found that a dose of $0.2-0.9$ (L/ha) showed an average decrease of $2 \%$ in the lady beetlepopulation and doses of $1.2(\mathrm{~L} / \mathrm{ha}$ ) alone caused $4 \%$ losses (Figure 2).

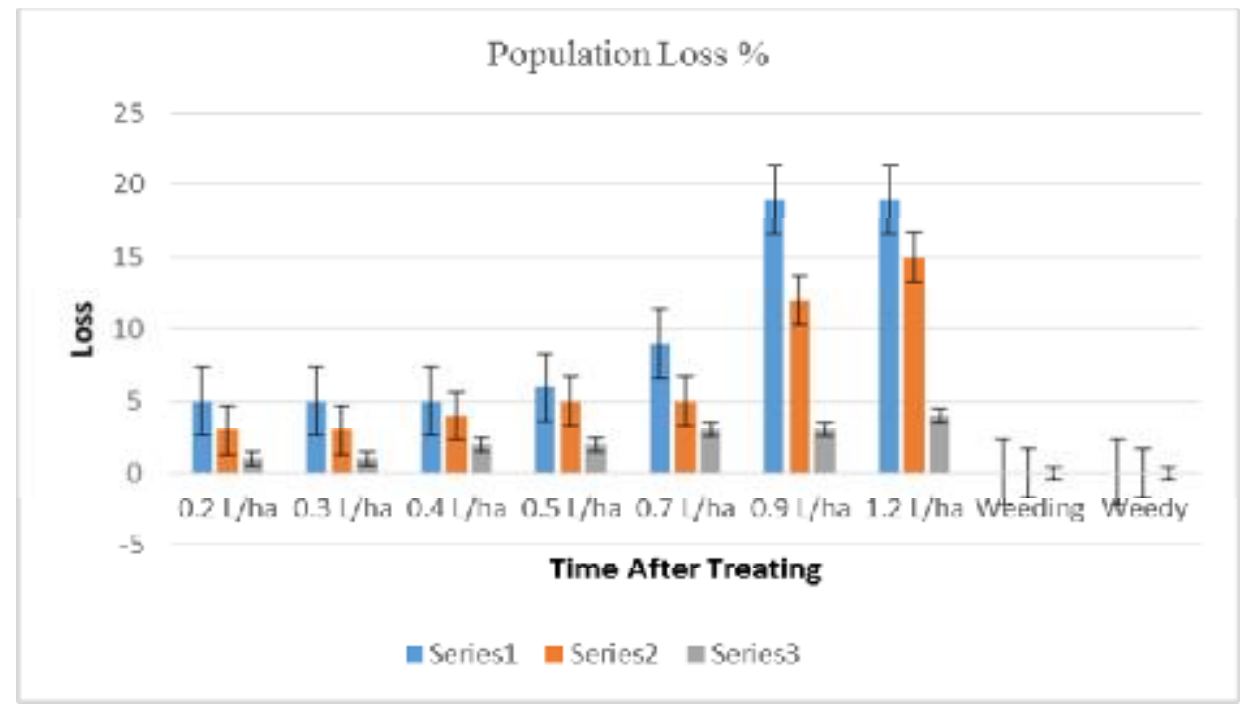

Figure 2. Lady Beetle Population Loss Percentage (48 Hours- series 1, One Week- series 2 and Three Week- series 3, after Treating Herbicide Imazethapyr) -2015 
It was concluded that spraying with Imazethapyr risks losses to a population of useful arthropods, the lady beetles. By increasing the dose of Imazethapyr, the ratio of losses will rise process. Within 48 hours of spraying and one week after spraying, risks and losses arise from the use of Imazethapyr; the third week after spraying, the ratio of losses is significantly reduced but the effects of high doses of Imazethapyr are visible at a population loss of $4 \%$. This shows the significance of the use of herbicides and suggests that the arthropods, as an indicator of EIQ will suffer losses at higher doses.

\section{Lady beetles larvae}

Samples that were collected taken in the first and second years of the experiment, hand-weeding showed no negative impacts on the population of lady beetles larvae after a period of 2 days, one week, and three weeks after applying the herbicide, Imazethapyr. However, the use of the herbicide at $0.2-0.7(\mathrm{~L} / \mathrm{ha}$ ) led to a $4 \%$ average decrease in the population of lady beetles larvae, while another dose of $0.9-2.1(\mathrm{~L} / \mathrm{ha}$ ) triggered a decrease of $13 \%$ in the larval population of ladybug larvae (Figure 3).

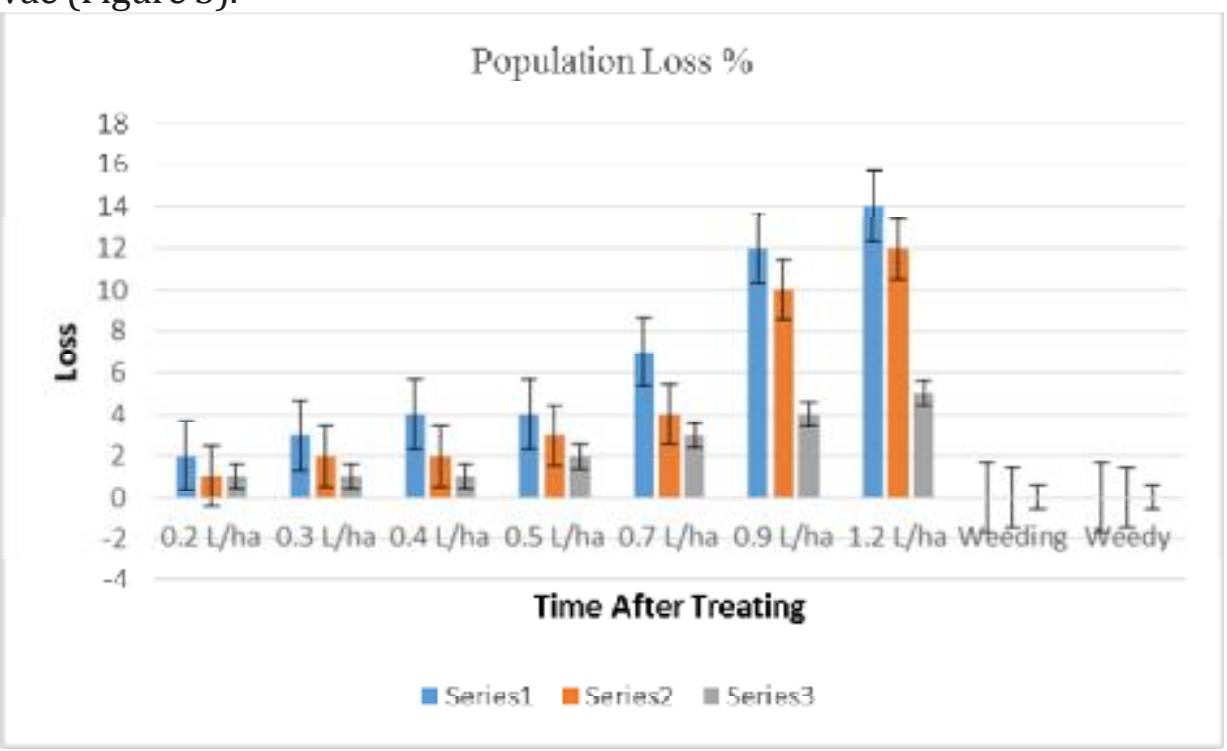

Figure 3. Lady Beetle Larvae Population Loss Percentage (48 Hours- series 1, One Week- series 2 and Three Week- series 3 after Treating Herbicide Imazethapyr) -2014

One week after applying the herbicide Imazethapyr, its negative effects on the population of lady beetles larvae was still observed. At this point, the decline in the larval population was $2.4 \%$ for Imazethapyr at $0.2-0.7(\mathrm{~L} / \mathrm{ha})$ and $11 \%$ at $0.9-1.2(\mathrm{~L} / \mathrm{ha})$. The rate of decline in the larval population was slower than during the first 02 days the herbicide treatment still had a continuously damaging effect on the larval population (Figure 3). These results were also consistent with the effect of doses of Imazethapyr on the adult lady beetles population. Three weeks after applying the herbicide, Imazethapyr, a sampling of lady beetles larvae showed a significant population decline. Examination of different Imazethapyr doses showed that doses of $0.2-0.9$ (L/ha) led to a $2 \%$ average decrease in the population of lady beetles larvae, while the dose of 1.2 (L/ha) decreased the larval population by an average of $5 \%$ (Figure 3).

Results pertaining to the second year of this study confirmed the results of first year, as they were nearly identical. The sampling procedures used during 2015 were identical to the procedures 
followed in the preceding year. The results obtained in 2015 showed that 2 days after applying the herbicide, the average decrease in the larvae population at $0.2-0.7$ (L/ha) was $5 \%$, whereas the average decrease of higher doses was 17\% (Figure 4). Even one week after applying the herbicide, the negative effects of Imazethapyr on the population density of lady beetles larvae was clearly noticed At this point, the population decline was $4 \%$ for doses of $0.2-0.7$ (L/ha) and $15 \%$ for doses of $0.9-1.2$ (L/ha) (figure 4). Three weeks after applying the herbicide, doses of $0.2-0.7$ (L/ha) led to an average $2 \%$ decrease in the lady beetles larvae, while doses of $0.9-1.2$ (L/ha) reduced the larval population by an average of $11 \%$ (Figure 4 ).

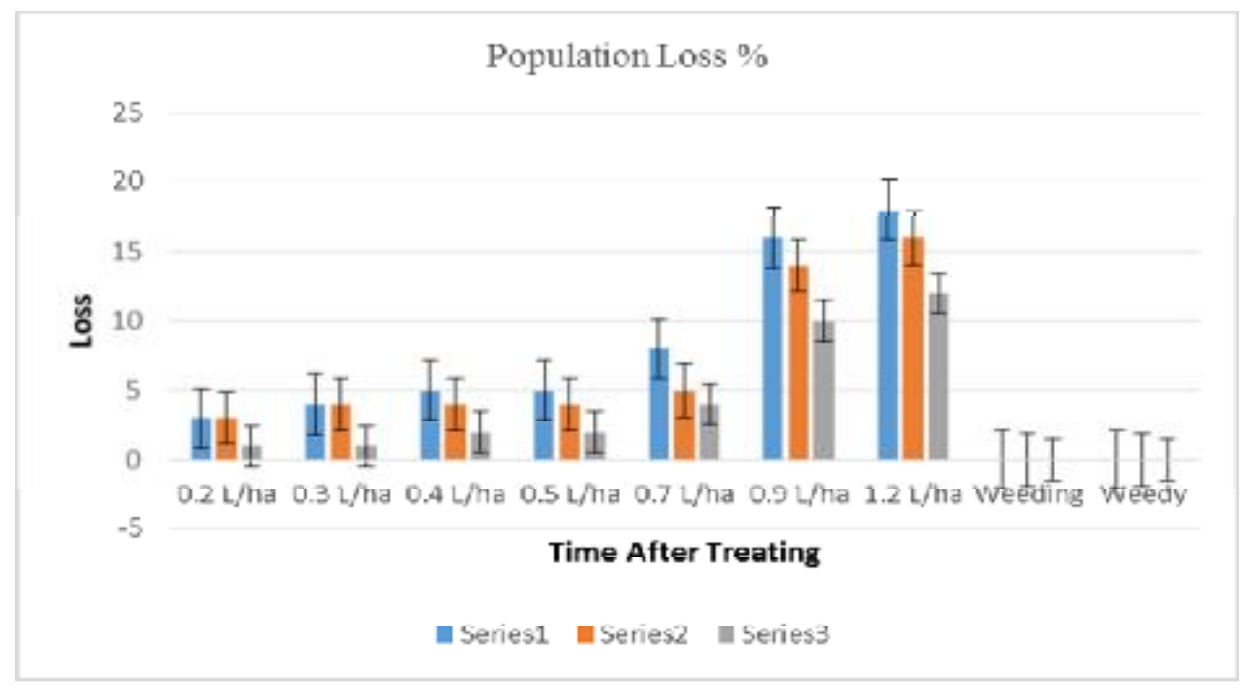

Figure 4. Lady Beetle Larvae Population Loss Percentage (48 Hours- series 1, One Week- series 2 and Three Week - series 3,after Treating Herbicide Imazethapyr) -2015

\section{Earwigs}

Data recorded on 2 days after application of herbicides during 2014, revealed that hand weeding and no hand weeding had no effect on the earwig's population. Different doses of Imazethapyr herbicide showed different effects on the population of earwigs. Doses ranging from 0.2 liters per hectare to the standard dose of 0.5 liters per hectare, led to an average decline of $5.5 \%$ in the earwig population. However, earwig losses were twice with doses at 0.7-1.2 liters per hectare (Figure 5). One week after spraying, the percentage of reduction in losses was entirely consistent with the results that were recorded on second day after spraying .Loss averages were $3 \%$ and $0.6 \%$ with doses of 0.2-0.5 and 0.7-1.2 liters per hectare, respectively. The loss rate was reduced compared to the first 48 hours, but the negative effects of Imazethapyr herbicide on earwigs are visible, especially when used in high doses (Figure 5). As in the case of lady beetles, three weeks after spraying and sampling, Imazethapyr effects on earwig population loss showed a significant decrease; with doses of 0.2-0.7 liters per hectare, earwig losses were only 1.6\%, while with two higher doses, an average of 3.5\% loss was observed (Figure 5).

Results in 2014, showed that, 48 hours after spraying, the average loss of the doses of 0.2 to 0.7 was equal to $5.8 \%$, but the losses of last dose were on average 14\% (Figure 6).

One week after application of spray materials at 0.2-0.7 liters per hectare, the loss rate was recorded 3.8\%whereas herbicide applied at 0.9-1.2 liters per hectare, the total loss rate was 9\% (Figure 6). Similarly, the results of sampling after three weeks of spraying showed that herbicide 
used at $0.2-0.5$ liters per hectare reduced only $01 \%$ of the earwig population, and another dose at 0.7-1.2 liters per hectare, 03\% earwig losses were recorded (Figure 6).

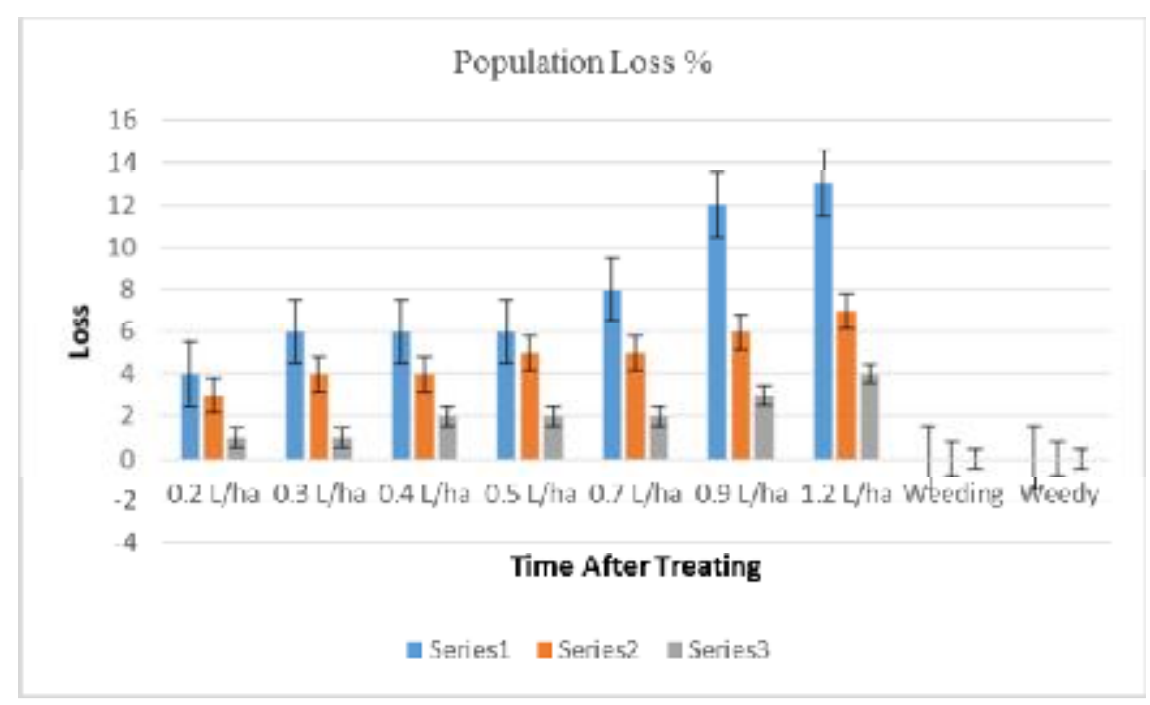

Figure 5. Earwigs Population Loss Percentage (48 Hours- series 1, One Week- series 2 and Three Week- series 3, after Treating Herbicide Imazethapyr) -2014

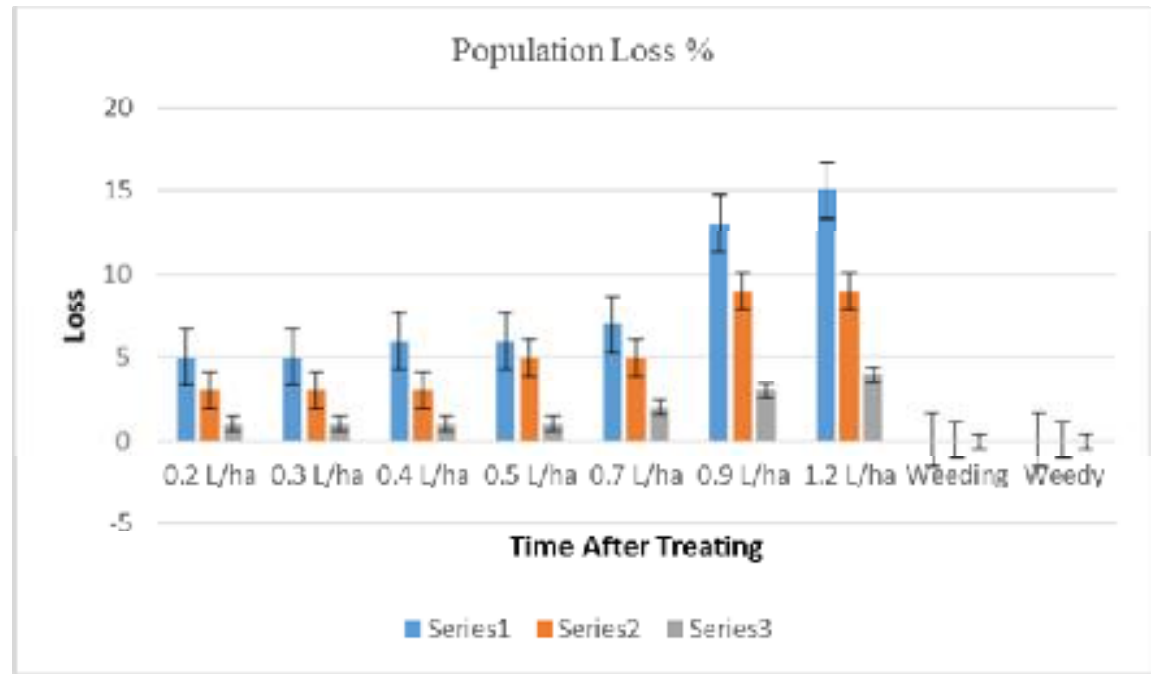

Figure 6. Earwigs Population Loss Percentage (48 Hours- series 1, One Week- series 2 and Three Weekseries 3, after Treating Herbicide Imazethapyr) -2015

\section{Earwig larvae}

Examination of the population of earwig larvae recorded in 2014 and 2015 showed that hand weeding had no negative effects on the earwig larvae population after 2 days, one weekand three weeks after applying the herbicide. Similarly, applying Imazethapyr at doses of 0.2-0.7 (L/ha) led to $7 \%$ average decrease in the earwig larvae population, while using herbicide doses of $0.9-2.1$ (L/ha) reduced the larval population by $17 \%$ (Figure 7 ).

One week after applying the herbicide, the decline in the earwig larvae population was $5 \%$ for doses of $0.2-0.7$ (L/ha) and $0.9 \%$ for doses of $0.9-1.2$ (L/ha) (Figure 7). Three weeks after 
applying the herbicide, doses of $0.2-0.7$ (L/ha) decreased the earwig larvae population by an average of $2 \%$, and higher doses led to an average $6.5 \%$ decrease in the larval population (Figure 7).

Samples taken during 2015 showed that02 days after applying the herbicide, the average damage of herbicide at $0.2-0.7$ was $8 \%$ reduction in the earwig larvae population, while the average damage of higher doses showed 19\% decline (Figure 8). One week after applying the herbicide, the effects of Imazethapyr on the population of earwig larvae were still evident; the decline in the larval population was $5 \%$ for doses of $0.2-0.7(\mathrm{~L} / \mathrm{ha}$ ) and $13 \%$ for doses of $0.9-1.2(\mathrm{~L} / \mathrm{ha}$ ) (Figure 8). Three weeks after applying the herbicide, Imazethapyr doses of $0.2-0.7$ (L/ha) decreased the earwigs larvae population by an average of $2 \%$. The average decrease in the earwig larvae population, as a result of Imazethapyr doses of 0.9 and 1.2, were $5 \%$ and $7 \%$, respectively (Figure 8).

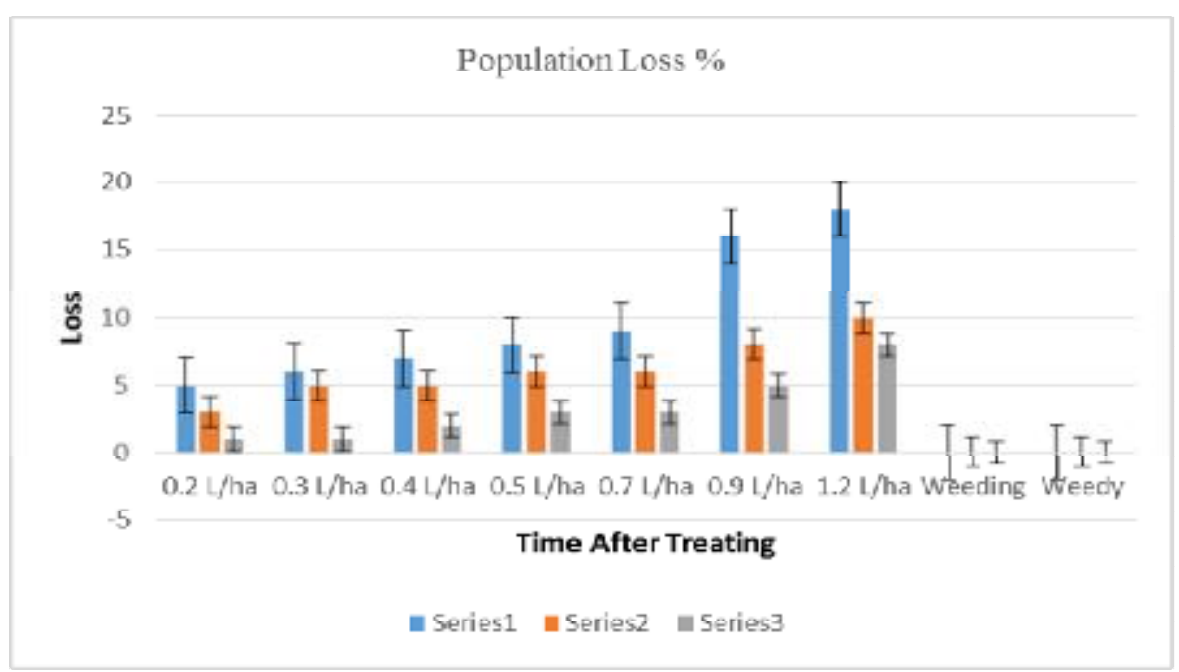

Figure 7. Earwig Larvae Population Loss Percentage (48 Hours- series 1, One Week- series 2 and Three Week- series 3, after Treating Herbicide Imazethapyr) -2014

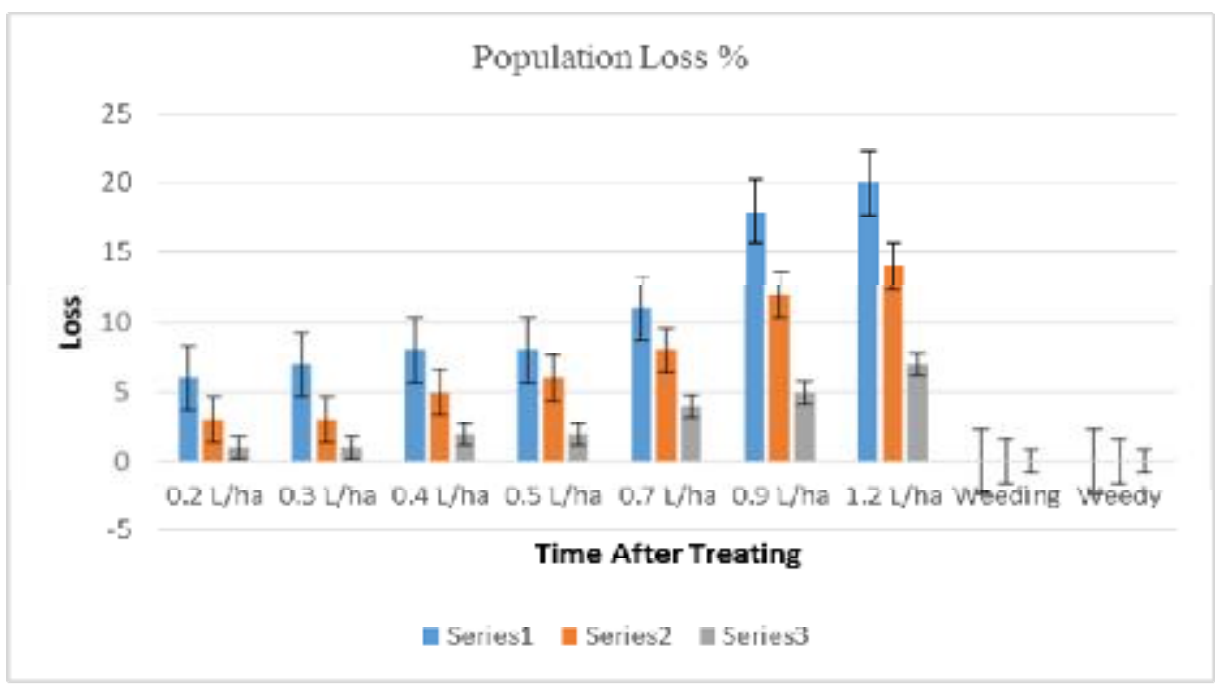

Figure 8. Earwig Larvae Population Loss Percentage (48 Hours- series 1, One Week- series 2 and Three Week- series 3, after Treating Herbicide Imazethapyr) -2015 


\section{Carabid beetles}

Data regarding the ill effects of herbicide on the average population density of Carabid beetles showed similar results pertaining to other insects, hand-weeding or the lack of weeding. It was seen that there was no no negative impact on the population of carabid beetles at 48 hours, one week, or three weeks after applying the treatments. Samples of Carabid beetles collected during first year of the study showed that Imazethapyr applied at $0.2-0.5(\mathrm{~L} / \mathrm{ha})$ triggered an average $4 \%$ decrease in the population of carabidbeetles; this average decrease was $7 \%$ for a dose of 0.7 (L/ha) and 20\% for the higher doses (Figure 9). The results showedthe lingering effects of high doses of Imazethapyr on the population of carabidbeetles. One week after applying the herbicide, for the lowest dose up to a dose of 0.7 (L/ha), the population decline was 3.8\%. An increased dosage intensified the decline in the population of carabidbeetles, and this decline reached $10 \%$ and $16 \%$ with the highest two doses (Figure 9). Three weeks after applying the herbicide, sampling demonstrated a decline in the population of carabid beetles, and the damaging effects of higher doses still lingered. At that point, the decline in population for doses of $0.2-0.7$ (L/ha) was $2 \%$, while the decline for higher doses was 9\% (Figure 9).

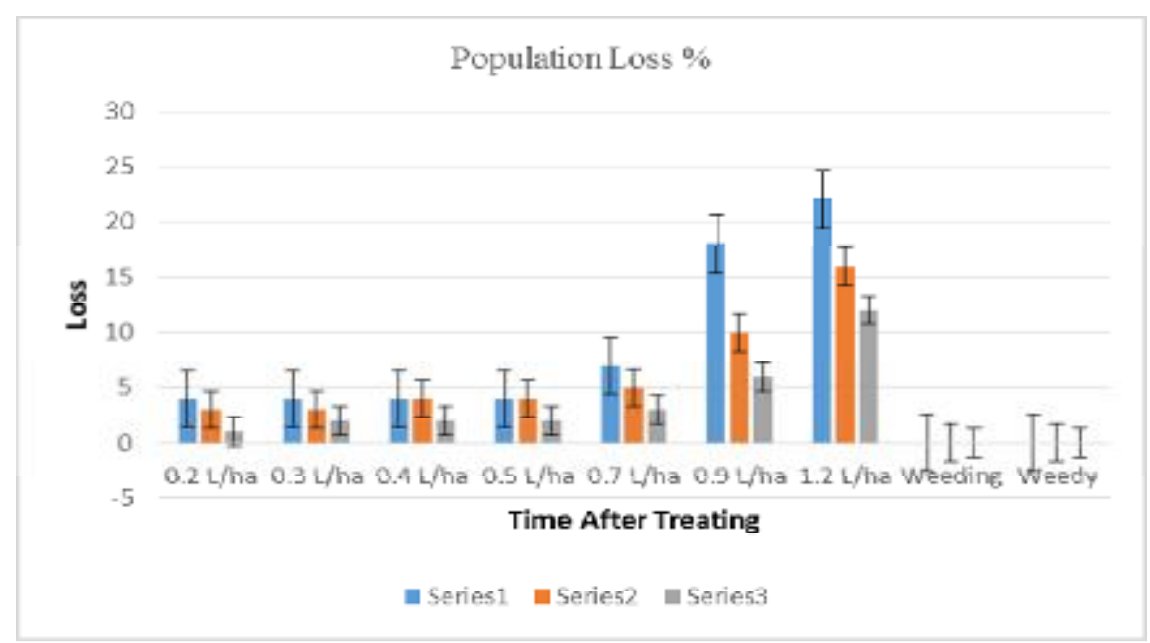

Figure 9. Carabid Beetles Population Loss Percentage (48 Hours- series 1, One Week- series 2 and Three Week- series 3, after Treating Herbicide Imazethapyr) -2014

The populations of carabid beetles in the years 2014 and 2015 were not identical, but the results pertaining to the second year confirmed the damage to the population of the preceding year. The damage to the population rates showed only marginal differences from year to year. Sampling procedures during 2015 were identical to those used in the preceding year. Results showed that 48 hours after applying the herbicide, the average damage of doses of 0.2-0.7 (L/ha) exhibited an $8.8 \%$ decline in the beetle population, while the average decline experienced at higher doses was $22 \%$, which was significantly higher than the population decline under lower doses (Figure 10). Similar to the results of the first year, the results of the second year showed that one week after applying the herbicide,the effects of Imazethapyr on the population of carabidbeetles were still evident, as the decline in population of carabidbeetles averaged $6.25 \%$ for doses of $0.2-0.5(\mathrm{~L} / \mathrm{ha})$ and averaged 15\% among higher doses (Figure 10). Three weeks after applying the herbicide, doses of $0.2-0.7$ (L/ha) had triggered an average $3.2 \%$ decrease in the population of carabidbeetles, but higher doses decreased their population by an average of $12.5 \%$ (Figure 10). 


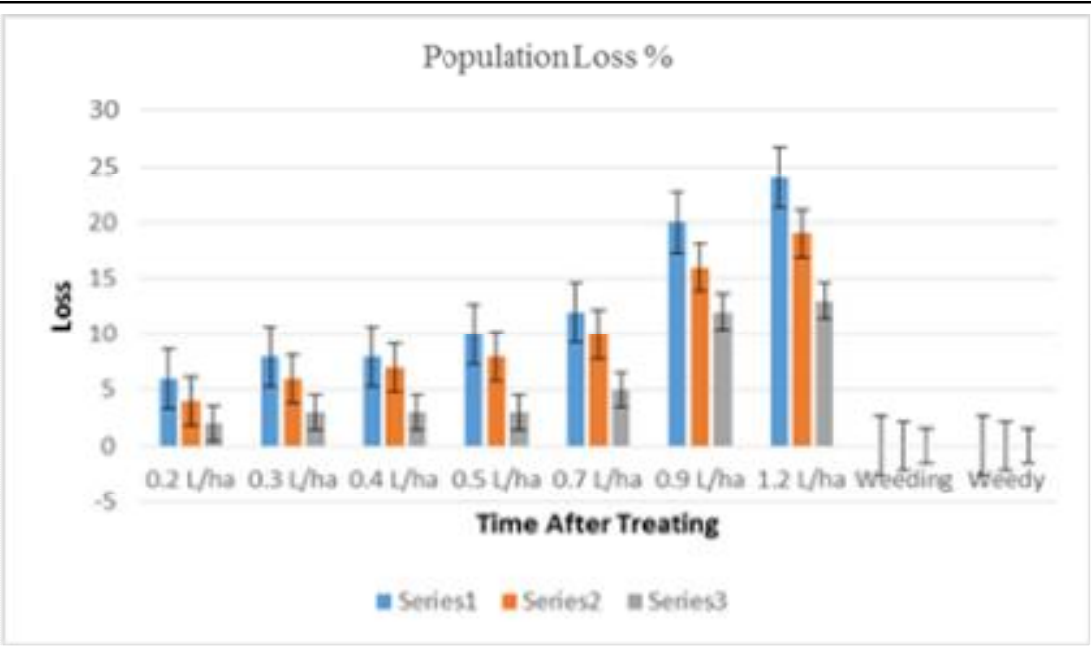

Figure 10. Carabid Beetles Population Loss Percentage (48 Hours- series 1, One Week- series 2 and Three Week- series 3, after Treating Herbicide Imazethapyr) -2015

\section{Carabid beetle larvae}

Hand-weeding or lack of weeding showed nonegative impacts on the population of carabidbeetle larvae at 48 hours, one week, or three weeks after applying the herbicide, Imazethapyr. As mentioned, a similar result was found for all the investigated insects.Samples from 2014 showed that 48 hours after applying the herbicide, the average decline at doses of $0.2-0.7(\mathrm{~L} / \mathrm{ha})$ in the larval population was $0.5 \%$, while the average decline in population for the two highest doses were $13 \%$ and 18\%, respectively (Figure 11). One week after applying the herbicide, sampling revealed that the effects Imazethapyr at doses of $0.2-0.7$ (L/ha) had decreased the population of carabid beetle larvae only $3 \%$, but the effects of the two highest doses of Imazethapyr showed an average decline of $9.5 \%$ in the larval population (Figure 11). Three weeks after spraying the herbicide, doses of $0.2-0.7$ (L/ha) caused an average 2\% decrease in the population of carabid beetle larvae, but the two highest doses caused an average population decrease of $7.5 \%$ (Figure 11), which is significantly higher than the effect of low doses, even three weeks after the initial application of the herbicide.

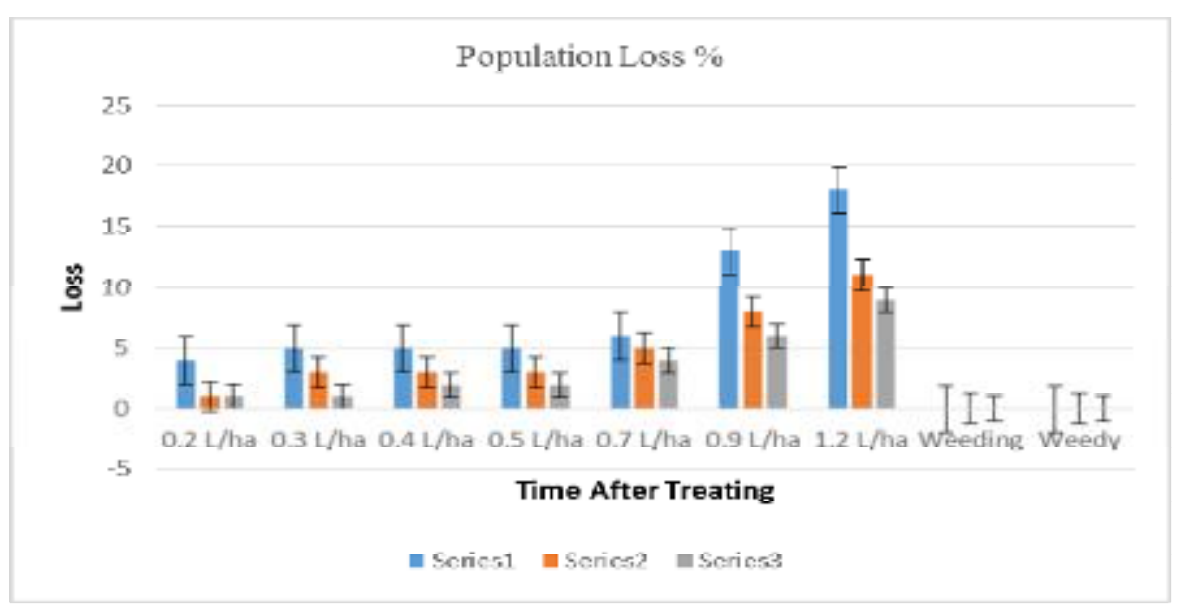

Figure 11. Carabid Beetles Larvae Population Loss Percentage (48 Hours- series 1, One Week- series 2 and Three Week- series 3, after Treating Herbicide Imazethapyr) -2014 
In samples from 2015, Imazethapyr doses of $0.2-0.5$ (L/ha) decreased the population of carabid beetle larvae by an average of $6.5 \%$. For the three highest doses, the population decrease averaged 11\%, 15\%, and 19\%. These findings signified the serious damage of high doses of Imazethapyr on the population of carabid beetle larvae (Figure 12). One week after applying the herbicide, the damaging effects of Imazethapyr on the population of carabid beetle larvae could still be observed; the population drop caused by doses of $0.2-0.5(\mathrm{~L} / \mathrm{ha})$ was $3.5 \%$, but the three highest doses reduced the larval population by $8 \%, 11 \%$, and 17\%, respectively (Figure 12). Three weeks after applying the herbicide, the effects of high doses of Imazethapyr on the carabid beetle larvae population still lingered, as the two highest doses reduced the larval population by $7 \%$ and $11 \%$, respectively (Figure 12 ).

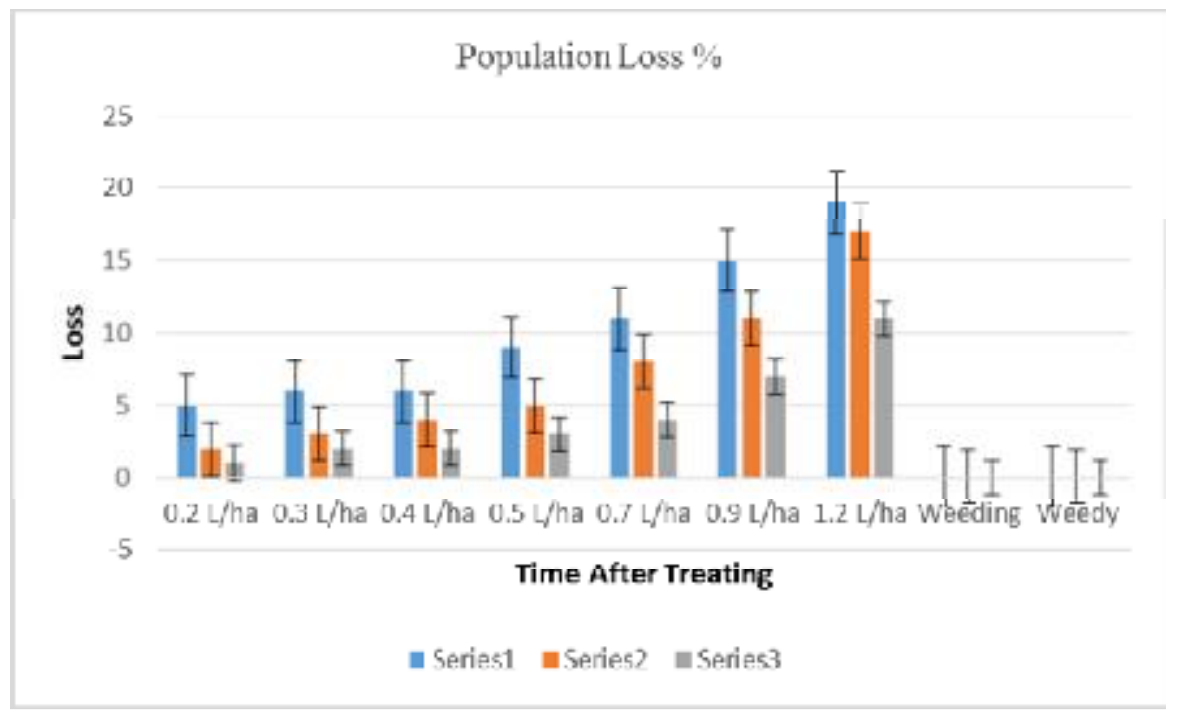

Figure 12. Carabid Beetles Larvae Population Loss Percentage (48 Hours- series 1, One Week- series 2 and Three Week- series 3, after Treating Herbicide Imazethapyr) -2015

Although the populations of carabidbeetlesin the years 2014 and 2015 were not identical, the results of the second year confirmed the results of the first year, because the population damage results displayed only marginal differences. Overall, this study clearly demonstrated that the use of Imazethapyr puts the population of carabid beetles, which can be counted among agriculture's beneficial organisms, at great risk. This risk increased with the increase in the applied herbicide dosage. During the first 48 hours and at the first week after applying Imazethapyr, this herbicide left obvious impacts on the population of both larvae and adult beetles, but the damage to the population decreased significantly in the third week. However, using a high dose of Imazethapyr extended its damaging effects, and this lingering effect highlighted the importance of using this herbicide in managed quantities. Due to the highly diversified range of insects in the farm and the results of the effects of herbicides on three groups of the largest populations of insects, the results showed that increasing doses of herbicides had negative and adverse impacts on the population of insects and their larvae in all three categories. This is a warning for excessive consumption of herbicides in the region and the world because farmers use inexplicably herbicides with very high doses. In addition, it is proposed to be considered examining the impact of the study herbicides on other insects in the farm on the agenda of researchers in the weed sections in the coming years. 


\section{Discussion}

A wide spectrum of insects was detected in alfalfa farm, but it may be explicitly stating that the main reason for choosing ladybird, earwig and carabid beetles can be attributed to the large population of these insects in the farm under study. According to the usefulness of these three groups of identified insects and a large number of them compared to other insects in the farm, so the effects of herbicides were examined on these three categories.

As soon as herbicide is applied to its target, a number of processes immediately begin to remove the compound from the original site of application. This removal is the process of environmental fate. For the herbicide which is intercepted by plants, the chemical may be taken up by the plant itself, may be washed off of the foliage by precipitation or irrigation onto the soil, may undergo photo degradation on plant surfaces, or may volatilize back into the air. Besides that, all living organisms in the soil will be affected by the herbicide.

Most herbicides are organic compounds and therefore basically unstable in the environment. Inherent instability is essential to prevent these materials from accumulating in the environment as compounds are repeatedly used. Accumulation of pesticides not only poses environmental hazards, but prohibits rotation to sensitive crops. Unfortunately, not all herbicides exhibit optimal stability properties, and therefore numerous examples of insufficient control (too little stability) or carryover (too much stability) have been reported. Furthermore, persistence in the environment prolongs exposure of the materials to forces that can cause movement of the herbicide away from the application site.

The herbicide that falls directly upon the soil or is washed onto the soil can undergo a number of processes which may be broken down into two main groupings: degradation and transport processes. Degradation processes include biological degradation by soil organisms and abiotic chemical and photochemical transformations. Transport of herbicides within the soil compartment can occur downward into the soil profile (leaching), across the soil surface (runoff), or into the air (volatilization). Each can be a combination of more fundamental processes including adsorption, convection, and diffusion. But always in the meantime, organisms and agents as Non-target are affected by using the herbicide. Always all insects in the soil will suffer from herbicides. The above results, alerts us to the dangers of herbicides. This topic will be more specific when apply high doses of herbicides. Herbicides are an integral part of agriculture, but their use, must comply with all environmental issues. All non-target organisms from herbicides in the soil like insects are at risk. It is incumbent upon us researchers that use of herbicides to be more careful to do.

\section{References}

Arnet, RH. (1973). The Beetles of the United States. Arbor Michigan, Am. Entomol., Inst., 1112 papers.

Borror, DJ, Triplehorn, CA, Johnson, NF. (1992). An Introduction to the study of insects. Sixth Edition. 875p. Saunders College bublishing.

Cooper, LP. (1992). Control of black field earwig, Nalalividipes (Dufour), in beetroot seedlings. Plant Protect. Quart., 7:112-113.

Costa, JT. (2006). The Other Insect Societies. Harvard University Press, Cambridge, 812 pages. 
Fox, TB, Landis, DA, Cardoso, FF, Difonzo, CD. (2004). Predators suppress Aphis glycines Matsumura population growth in soybean. Environ. Entomol., 33:608-618.

Gaetan du Chatenet (1986). Guide des Coleopteresd'Europe. 480p. DelachauxetNiestle.

Grimaldi, D, Engel, MS. (2005). Evolution of the Insects. Cambridge University Press, Cambridge, New York.

Günther, K, Herter, K. (1974). Ordnung Dermaptera (Ohrwürmer). In: Helmcke J-G, Starck D, Wermuth H (eds) Kükenthal'sHandbuch Der Zoologie, 2nd edn, Vol. 4, pt 2, pp 1-158. Walter de Gruyter, Berlin, New York

Haas, F, Hwen, JTC, Tang, HB. (2012). New evidence on the mechanics of wing unfolding in Dermaptera. Arthropod Systemat. Phylog., 70:95-105.

Heap, I. (2012). International survey of herbicide resistance weeds. Online Internet. 10 May 2012. Availal.www.weedscience.com

Khanjani, M, Soleimanipari, MJ. (2005). Integrated pest management, diseases and weeds in alfalfa in Iran, publication of research, education and agricultural extension, First Edition, $222 \mathrm{p}$.

Kharboutli, MS, Mack, TP. (1993). Comparison of three methods for sampling arthropod pests and their natural enemies in peanut fields. J. Econom. Entomol., 86:1802-1810.

Koch, RL, Hutchinson, WD, Venette, RC, Heimpel, GE. (2003). Susceptibility of immature monarch butterXy, Danausplexippus(Lepidoptera: Nymphalidae) to predation by Harmoniaaxyridis(Coleoptera: Coccinellidae). Biol. Control, 28:265-270.

Koch, RL. (2003). The multicolored Asian lady beetle, Harmoniaaxyridis: a review of its biology, uses in biological control, and non-target impacts. J. Insect Sci., 3:1-16.

Kromp, B. (1999). Carabid beetles in sustainable agriculture: a review on pest control efficacy, cultivation impacts and enhancement. Agricult. Eco. Environ., 74:187-228.

Kvoach, J, Petzoldt, C, Degil, J, Tette, J. (1992). A method to measure the environmental impact of pesticides.

Levitan, L. (1997). An overview of pesticides impact assessment systems. Workshop on pesticide Risk Indicators. Copenhagen, Denmark. April, 21-23.

Lindroth, CH. (1974). Handbok for the identification of british insects (Coleoptera: Carabidae). Royal Entomol. Soc. London, 4(2):148 papers.

Lobl, I, Smetana, A. (2003). Catalogue of PalaearticColeoptra. Volume I. ArchostemataMyxophaga-Adephaga. Apollo Books, 819 papers.

Lovei, GL, Sunderland, KD. (1996). Ecology and behavior of ground beetls (Coleoptera: Carabidae). Ann. Rev. Entomol., 41:231-56. 
Mighani, F, Mirvakili, A, Jahedi, MA, Baghestani, V, Shimi, P, (2011). Study of 2,4-DB (Botres) based Efficacy in Weed Control in Established Alfalfa (Medicago sativa), Iranian Journal of weed science, 2(6):67-77.

Morvan, P. (1974a). Contribution a la connaisssance des coleopteres Carabidae de l'Iran. J. Entomol. Soc. Iran, 1(2):129-141.

Morvan, P. (1974b). Nouveaux coleopteres Carabiquesd' Iran. J. Entomol. Soc. Iran, 2(1):117

Morvan, P. (1974c). Nouveaux coleopteres Carabiquesd' Iran. J. Entomol. Soc. Iran, 1(2):143156.

Morvan, P. (1976). Nouveaux coleopteres Carabiquesd' Iran. J. Entomol. Soc. Iran, 3(1,2):1540

Morvan, P. (1977). Contribution a la connaisssance des coleopteres Carabidae de l'Iran. J. Entomol. Soc. Iran, 4(1,2):21-60.

Morvan, P. (1981). Contribution a la connaisssance des coleopteres Carabidae de l'Iran. J. Entomol. Soc. Iran, 6(1,2):9-46.

Myhre, CD, Loeppky, HA, Stevenson, FC. (1998). Mon-37500 for weed control and alfalfa seed production. Weed Technol., 3:810-815.

Popham, EJ. (2000). The geographical distribution of the Dermaptera (Insecta) with reference to continental drift. J. Natural History, 34:2007-2027.

Prado, RD, Torres, LG. Jorrin, J. (1997). Weed and cop Resistance to Herbicide. Kluwer Academic Publisher.

Raoofi, M, Giti, S, Daneshian, J, Giti, S. (2013). Application of the flamethrower in the management of weeds in alfalfa and its effect on soil microphone. The Fifth Conference of weeds. Tehran University. September 2013.

Raoofi, M, Giti, S, Khanjani, M , Daneshian, J. (2013). Evaluating the efficiency of the combined use of the herbicides to control weeds in alfalfa and its impact on the environment. Environment conference. Technical University of ShahidMofateh, Hamadan.

Raoofi, M, Khanjani, M, Giti, S, Daneshian, J. (2013). Evaluating the efficiency of the flamethrower in weed management and pest control of Curculionidae in alfalfa fields. National conference on applied research in science and engineering. University of Takestan.

Raoofi, M, Giti, S, Atlasi Pak, V, Mahzari, S. (2013). Assess the effect of different herbicides along with cytogate on weed control Iranian bitter flixweed, sorrel, Salsify and dandelion in alfalfa. The second national conference on organic farming and conventional. The University of MohagheghArdabili. 
Raoofi, M, Giti, S, Kalhornia, H. (2014). PC Gate and its role in protecting of the environment by reducing the use of chemical pesticides. The National Conference of specialized research environment. Technical University of ShahidMofateh, Hamedan.

Raoofi, M, Khanjani, M, Daneshian, J, Giti, S. (2014). Integrated Weed Management in Perennial Alfalfa (Medicago sativa L.) and theirs effects on soil's micro fauna. Int. J. Farm. All. Sci., 4:430-435.

Renz DCF, Kevan DKMcE (1991). Dermaptera. In: CSIRO Division of Entomology (ed.) The Insects of Australia, 2ndedn, pp 360-368. Cornell University Press, Ithaca, NY.

Sakai, S. (1982). A new proposed classification of the Dermaptera with special reference to the check-list of the Dermaptera of the world. Bull. Daito Bunka University, 20:1-108.

Sakai, S. (1985). Dermapterorum Catalogus XVI-XVIII: Iconographia I-III. Pygidicranidae and Diplatyidae. DaitoBunka University, Tokyo.

Sakai, S. (1987a) Dermapterorum Catalogus XIX-XX: Iconographia IV-V. Chelisochidae and Anisolabididae. Daito Bunka University, Tokyo.

Sakai, S. (1990). Dermapterorum Catalogus XXI-XXII: Iconographia VI-VII. Labiduridae and Apachyidae. Daito Bunka University, Tokyo.

Sakai, S. (1991). Dermapterorum Catalogus XXIII: Iconographia VIII. Spongiphoridae I. Daito Bunka University, Tokyo.

Sakai, S. (1992). Dermapterorum Catalogus XXIV: Iconographia VIII. Spongiphoridae II. Daito Bunka University, Tokyo.

Sakai, S. (1993). Dermapterorum Catalogus XXV: Iconographia IX. Spongiphoridae III. Daito Bunka University, Tokyo.

Sakai, S. (1994). Dermapterorum Catalogus XXVI: Iconographia X. Forficulidae. Daito Bunka University, Tokyo.

Sakai, S. (1995a). Dermapterorum Catalogus XXVII: Iconographia XI. Forficulidae. Daito Bunka University, Tokyo.

Sakai, S. (1995b). Dermapterorum Catalogus XXVIII: Iconographia XII. Forficulidae. Daito Bunka University, Tokyo.

Sakai, S. (1995c). Dermapterorum Catalogus XXIX: Iconographia XIII. Forficulidae. Daito Bunka University,Tokyo.

Sakai, S. (1995d). Dermapterorum Catalogus XXX: Iconographia XIV. Forficulidae. Daito Bunka University, Tokyo.Steinmann H (1986) Dermaptera. Catadermaptera I. Das Tierreich102, 1-343.

Steinmann, H. (1989a). Dermaptera. Catadermaptera II. Das Tierreich, 105:1-504. 
Steinmann, H. (1989b). World Catalogue of Dermaptera. Kluwer Academic Publishers, Dordrecht.

Steinmann, H. (1990). Dermaptera. Eudermaptera I. Das Tierreich, 106:1-558.

Steinmann, H. (1993). Dermaptera. Eudermaptera II. Das Tierreich, 108:1-711.

Tedders, WL, Schaefer, PW, (1994). Release and establishment of Harmoniaaxyridis(Coleoptera: Coccinellidae) in the southeastern United States. Ent. New., 105:228-243.

Trautner, J. (1988). Tiger beetles, ground beetles: Illustrated key to the Cicindellidae and Carabidae of Europe. Unipub Pub. 488 papers.

Triplehorn, CA, Johnson, NF. (2005). Borror and Delong's introduction to the study of insects. $7^{\text {th }}$ Edition. Thomson Brooks/Cole, Belmont, USA. 864 pages.

Zand, A, Baghestani, MA, Bitarafan, M, Shimi, P. (2007). Manual herbicides piet in Iran, Mashhad University Jihad Press, first edition, 48 pages.

Zand, E, Baghestani, MA. Nezamabadi, N, Shimi, P. (2010). A guide for herbicide in Iran. University Press Center (In Persian with English summary.

How to cite this article: Mohammad Raoofi, Mohammad Taghi Alebrahim, Somayeh Giti, Mohammad Khanjani, Mahnaz Akbari, Mohammad Ali Baghestani, Studies on the Effect of Herbicide, Imazethapyr on Population Loss Percentage of Natural Enemies in Established Alfalfa Farms in Iran. International Journal of Advanced Biological and Biomedical Research, 2020, 8(1), 40-57. Link: http://www.ijabbr.com/article 36264.html 